\title{
Preparing And Getting Ready For A Recruitment Competition « CAPEPS » : The Effect Of Group Work On The Experience's Construction Of Different Students Profiles
}

\author{
Youssef Maamria $^{1}$, Prof. Jérome Guérin ${ }^{2}$, Prof. Catherine Archieri ${ }^{3}$ \\ CREAD-University of Western Brittany UBO Brest France
}

\begin{abstract}
This oral presentation brings light to a scientific survey that is carried out as part of a $\mathrm{PhD}$ research about the construction of students experience in the Master degree training "trades of education and training" (MEEF) specialty physical education and sports (EPS).

The study aims to understand and explain how first-year MEEF Master's students prepare and get ready for the CAPEPS (national teacher's recruitment competition). It is part of a research program that articulates two theoretical approaches, the socio-technical approach (Albero, $2010 \mathrm{a} / \mathrm{b} / \mathrm{c}$ ) and the "Course of Action" program (Theureau, 2015). This combination of two theoretical approaches makes it possible to mobilize a conceptual apparatus to understand the complexity of the development of individual's activity in training environments as It aims also to provide assistance to the construction of sustainable training environments, by offering praxeological tracks (Albero, Brassac, 2013).

The study began at the beginning of the training with participatory observation (Laplantine, 1996). The researcher has participated in the courses given to the students by taking ethnographic notes, then asking them to conduct informal exchanges about their training activities as well as semi-direct interviews.

The first analyses allowed us to make initial observations. First, four groups were identified with specific characteristics. Each group is composed of four to five students. The groups differ from each other in the nature of the activities related to "preparing and getting ready" for action" in a non-academic context, "informal space". Each group of students has set up a specific work organization, which evolves according to the periods of training.
\end{abstract}

Keywords: Preparing for action; experience; transformation; human activity; training 